\title{
|NTRODUÇÃO AO DEBATE SOBRE AS POLÍTICAS OFICIAIS NO CAMPO CRIMINAL
}

Cezar Bueno de Lima

Professor de Sociologia Geral e Jurídica da Unifil e PUC - Campus Londrina.

E-mail: cebueno@rla01.pucpr.br

\section{Resumo}

O processo de globalização econômica e financeira atual tem provocado respostas contraditórias na formulação de políticas criminais por parte da burocracia estatal. De um lado, sob forte influência do pensamento econômico neoclássico, surge, no reino unido, a teoria da normalização do crime qualificando o ato criminal como uma opção racional de escolha, uma questão de oportunidade mediante a qual os delinqüentes calculam racionalmente suas ações. De outro lado, surge, nos EUA, o movimento de defesa da lei e da ordem, que propõe tolerância zero ao crime mediante a ampliação do direito penal e o recrudescimento da resposta criminal estatal. Para os defensores da descriminalização e do abolicionismo a utopia da sociedade de controle favorável ao aumento da punição e mudanças de alvo para administrar o crime ignora o fato da existência de uma sociedade sem penas a qual se manifesta através da cifra negra, diferença entre infrações denunciadas na polícia e aquelas efetivamente julgadas.

Palavras-chave: globalização, estado, crime, punição, descriminalização, abolição da pena

ois adolescentes ${ }^{1}$, o primeiro conhecido por Japonês e o segundo por Lázaro ambos com aproximadamente 14 anos de idade cometeram mais um roubo na região metropolitana de Londrina PR no ano de 2000.

${ }^{1} \mathrm{O}$ relato dos atos infracionais em questão foi informado pelo professor de filosofia da Unifil-Londrina, Joaquim Pacheco de Lima. 
Desta vez, os adolescentes mantiveram um casal de idosos em cativeiro extorquindo-lhes um video-cassete, uma fritadeira, uma máquina fotográfica e mais $\mathrm{R} \$ 70,00$ em dinheiro.

A ação criminal em questão foi, segundo relato dos adolescentes envolvidos, desvendada do seguinte modo: por volta das 19 horas, a política militar apropriou-se dos objetos roubados que estavam sob o poder dos adolescentes e, numa área florestal, próxima do local do crime, os agentes policiais soltaram-nos dizendo o seguinte: vocês não nos viram e nós não nos encontramos. Passados dois meses, os adolescentes foram detidos por furto numa outra residência e encaminhados à Promotoria de Justiça, a qual, após conversas com os pais dos garotos, os liberou.

Quanto aos perfis familiar e econômico dos adolescentes infratores pode-se constatar que Lázaro possui mãe desconhecida e que seu pai fugiu da penitenciária do Estado do Paraná (Curitiba) onde cumpria pena por tráfico de drogas. O pai de Lázaro possui diversas passagens pela polícia por prática de homicídios, roubos e furtos. Lázaro vive com a avó cujo ganho provém de uma pensão do marido, já falecido. Problemas de psicose e esclerose acompanham a combalida saúde da avó do adolescente infrator. Não obstante a distância geográfica que separa Lázaro de seu pai, este, por telefone, orienta o filho no exercício do tráfico de droga. A casa em que Lázaro reside com sua avó funciona como boca de fumo.

No caso do segundo adolescente infrator sabe-se que seu pai abandonou a mulher e seis filhos, três adolescentes do sexo feminino e três do sexo masculino. Dentre as adolescentes, duas "ganham a vida" prostituindo-se na Avenida Tiradentes (Londrina-PR). Quanto aos adolescentes masculinos, um deles é deficiente mental por consumo abusivo de droga, crack.

A descrição das características da ação infracional e dos perfis familiar e econômico dos agentes envolvidos é teoricamente relevante, uma vez que esse tipo de ato infracional e características mencionadas se aplicam a uma quantidade significativa de ações infracionais praticadas na região metropolitana de Londrina-PR. Daí, a importância de fazer uma reflexão sociológica sobre os mecanismos oficiais e teóricos vigentes de resolução dos conflitos criminais contra a pessoa e o patrimônio, na sociedade atual. 
O presente artigo visa expor algumas questões conceituais que abordam o fenômeno da criminalidade no âmbito das ciências sociais no intuito de contribuir para uma melhor compreensão dos motivos que alimentam o modo de atuação e a crença legitimadora da intervenção da burocracia estatal visando combater uma duvidosa escalada da ação criminal. Dentre os elementos teóricos abordados discutir-se-á a relação entre globalização, Estado e as contradições das políticas criminais adotadas em resposta aos atos infracionais.

\section{Globalização e Reestruturaçao da Política Criminal Estatal}

Tendo em vista o propósito desse artigo, optou-se por fazer uma breve discussão sobre as abordagens teóricas marxistas e neoliberal com base nos diversos autore ${ }^{2}$ que fazem uma reflexão sobre o atual processo de globalização.

O processo de globalização em curso pode ser entendido a partir de duas perspectivas teóricas distintas. De acordo com a teoria marxista, (CHESNAIS, 2001), trata-se de um fenômeno que do ponto de vista econômico, financeiro, político e militar produz relações assimétricas e hierárquicas entre países capitalistas centrais e periféricos. A partir dessa assimetria de poder entre nações e estados, certas demandas substantivas no campo da economia, da política estatal, da cultura e estratégicas de segurança que dominam a agenda de discussão entre os países e organismos internacionais tendem a obedecer a uma relação de subordinação hierárquica que vai do "núcleo duro" à periferia do sistema.

Os EUA são um exemplo específico dessa relação assimétrica por ser o país que detém o poder hegemônico no campo econômico, político e militar cuja evidência se manifesta na esfera das relações internacionais. No setor das políticas criminais, Nova York é o local onde surge o termo "tolerância zero", rapidamente disseminado em outras partes do continente (México, Argentina e Brasil) na tentativa de enfrentar a escalada dos conflitos criminais nesses países.

\footnotetext{
${ }^{2}$ Diversos autores, como Boaventura Sousa Santos (2000) e Dowbor, Ianni, Resende (1998), têm discutido sobre o tema no campo das Ciências Sociais.
} 
A caraterização marxista do processo de globalização em curso é refutada por Ohmae (1999), segundo o qual o termo globalização coincide com o fim do conceito de Estado-Nação construído a partir das revoluções econômica e política européia do século XIX.

Atualmente, afirma Ohmae (1999), assiste-se ao colapso da idéia de Estado-nação. Numa economia sem fronteiras, diz o autor, as pessoas têm melhor acesso a produtos de baixo custo e de boa qualidade "quando não são fabricados no próprio país". No plano da comunicação, povos afastados geograficamente e distintos culturalmente estão todos vinculados em razão do potencial revolucionário da informação global.

Um exemplo disso provém dos adolescentes. Estes, que são milhões em todo mundo, crescem num ambiente repleto de multimídia e adquirem modos de ser e de comportamento muito mais parecidos uns com os outros comparativamente aos membros das gerações mais velhas de suas próprias culturas. Diante da transformação econômica e cultural em questão, qualquer reflexão teórica que tome o Estado-nação como parâmetro de análise está fadada ao fracasso.

As crises econômicas e políticas que acompanham os países em face da globalização resultam de dois fatores: escassa prosperidade econômica e aumento das informações sobre o estilo de vida no exterior. É o caso, por exemplo, dos EUA que impulsionam expectativas muito rapidamente gerando um ambiente propício para que "a inveja e o ressentimento comecem a se espalhar" exigindo a intervenção populista do Estado em direção a uma política distributiva.

A raiz social desse descontentamento generalizado, diz Ohmae, está na forma intervencionista que assume o Estado através de políticas de subsidio. Esse modelo de intervenção é uma característica da tirania da democracia atual cuja vocação tem sido "conceder pesos iguais aos votos antes que sejam levadas em conta as contribuições para a manutenção da sociedade como um todo". Esse artificialismo vinculado às políticas distributivas definidas pelo poder tem por consequiência levar o governo a fazer empréstimos sem lastros com promessa de resgate a longo prazo, hipotecando o destino das gerações futuras.

As consequiências desse processo político intervencionista, avalia Ohmae (1999), é criar vícios, comprar votos e quanto mais funciona maior o apetite em níveis cada vez mais elevados. Esse modelo 
pode assumir um ponto, sem retorno, em que a maioria subsidiada e suprida do mínimo público não terá necessidade nem incentivo para permitir a busca de um equilíbrio fiscal sustentável.

As soluções propostas pelo autor para inverter esse quadro são: primeiro, fechar a torneira dos subsídios através de desregulamentação, privatização da infra-estrutura, decréscimo da mãode-obra empregada no setor público; segundo, limitar o poder político do governo central às questões de segurança e moeda; fortalecer a idéia dos estados-regiões, concedendo autonomia às unidades federativas no campo das transações econômicas internacionais.

É interessante avaliar como esse modelo proposto de privatização do Estado estabelece correspondência com as correntes teóricas no âmbito da política criminal.

\section{Economia, Estado e o Novo Discurso Criminal}

A partir de 1970 (GARLAND, 1999, p.64), foi montado no Reino Unido um discurso criminal com base na "teoria da escolha racional", "da teoria da atividade de rotina", "do crime como oportunidade" e "da prevenção da criminalidade situacional", desembocando nas "novas criminologias da vida cotidiana". O estereótipo de delinqüente muda de lugar. O novo infrator calcula suas ações, e a maior parte dos crimes converte-se numa questão de oportunidade. A melhor reposta seria, portanto, tornar as coisas mais difíceis para os delinqüentes.

Garland (1999) afirma que "uma linguagem analítica do risco, da racionalidade, da escolha, da probabilidade, da determinação de alvos, da oferta e da demanda de ocasiões", transfere as formas econômicas de raciocínio e de cálculo para o campo da criminologia. Novos objetivos tais como: compensação, controle de custo, redução dos danos etc., são definidos pela criação da imagem do "criminoso racional". Quanto à imagem da vítima, ela aparece como "fornecedora de ocasiões criminais".

Esse novo modelo de pensamento destrói considerações de caráter psicológico e sociológico utilizadas no séc. XX e formula uma nova concepção de "delinqüente criminal". A partir desse esquema de reflexão, procura-se repensar as dinâmicas da criminalidade e do castigo 
em termos pseudo-econômicos. Se o crime não for uma "escolha racional" fica mais difícil combatê-lo.

Esse modelo de análise surgiu no setor privado (companhias de seguro, empresas comerciais e de segurança privada) com o objetivo de "reduzir os custos" do crime que lhes pesam sobre os ombros. Esse raciocínio comercial e fundado no seguro acerca da repressão criminal procura diminuir ou deslocar os custos do crime em direção, não do castigo, mas da "prevenção," de reduzir o "risco" antes que garantir a justiça.

Esse modelo de pensamento, após os anos de 1980, passou a influenciar os organismos e práticas do Estado, sobretudo entre os setores profissionais ligados às concepções sociais e legais da criminalidade. Esse tipo de análise, tributário das concepções econômicas neoclássicas, forma o conjunto da "teoria da escolha racional", que vê no crime uma questão de oportunidade ocasional.

$\mathrm{O}$ ato criminal converte-se numa rotina, algo que acontece no curso normal das coisas e não mais uma perturbação social que requer explicações especiais. A conduta cotidiana da vida econômica e social "fornece infindáveis ocasiões" de transação ilegítima. As ações criminais são vistas como atos "regulares, previsíveis e sistemáticos", como um acidente de trânsito. Nesse sentido as ações contra o crime devem recair, não sobre pessoas desviantes mas, preferencialmente, sobre ação concebida para governar os hábitos sociais e econômicos (GARLAND, 1999, p.66).

Em oposição às afirmações da criminologia clássica ${ }^{3}$ que vincula a ação criminal à existência de patologias individuais e déficit de socialização, a teoria da escolha racional vale-se dos esquemas clássicos de "motivação" econômica. Para o sujeito incriminado trata-se "de uma ocasião, uma escolha de carreira, um meio de conseguir emoções fortes ou vingar-se". Para a vítima ou o público, o crime constitui "um risco" que deve ser calculado ou um "acidente" a ser evitado e não uma "aberração moral" que exija explicações sofisticadas.

Ao decretar a incapacidade do aparato repressivo do Estado de lidar com o problema da criminalidade, essas teorias procuram desarmar a

\footnotetext{
${ }^{3}$ Ver, por exemplo, a abordagem que faz Alexando Baratta (2002) no capítulo "escola positiva e explicação patológica da criminalidade".
} 
pesada e deficiente burocracia estatal em busca de outros padrões de intervenção. $\mathrm{O}$ estabelecimento de novos programas de ação devem "influenciar a conduta das vítimas potenciais, armar os alvos vulneráveis, melhorar a segurança em zonas perigosas e reestruturar as rotinas da vida cotidiana que têm propiciada desagradáveis ocasiões para o crime."

A erosão da confiança da sociedade atual nas "eventualidades das penas dissuasivas" decorre da duvidosa capacidade da polícia de prender os bandidos ou da vã esperança de que se possa "ensinar o domínio de si aos jovens cidadãos". A nova ordem social requer, como imperativo, a necessidade de substituir o dinheiro vivo por cartões de crédito, de embutir travas nas colunas de direção dos automóveis, contratar vigias nos estabelecimentos, colocar circuitos internos de televisão, coordenar os horários de fechamento das discotecas rivais etc. Essa nova concepção da normalização do crime justifica e abona a reforma neoliberal do Estado ao transferir para os setores privados a responsabilidade estatal pela segurança pública.

Dentro desse quadro, ganham força propostas políticas de defesa de reformas transferindo, do Estado para os grupos privados, a responsabilidade pela gestão dos conflitos criminais. Esse modelo de política criminal desenvolvido no Reino Unido, sob forte influência do pensamento econômico neoliberal, não é hegemônico e, em determinados aspectos, contrasta abertamente com certos princípios do chamado "realismo penal" adotados pelo aparato de Estado norteamericano no campo da política criminal.

\section{A Opçao Norte-Americana Por Ủma Política Criminal de Tolerância Zero}

Nos EUA, a redefinição das missões do Estado parte de princípios quase dogmáticos de reduzir o seu papel social e de ampliar sua intervenção penal.

Os órgãos de Estado norte-americano encarregados de promover o rigor penal resultaram na quadruplicação da população carcerária. As diretrizes da política policial e judiciária fizeram de Nova York a vitrine mundial da doutrina da "tolerância zero" ao passar às forças da ordem um cheque em branco para perseguir agressivamente 
a pequena delinqüência e reprimir os mendigos e os sem-teto nos bairros deserdados. Isso vem, segundo Wacquant (2001), acompanhado da vulgarização da teoria da "vidraça quebrada" que é um empréstimo do ditado popular "quem rouba um ovo, rouba um boi". A premissa dessa teoria conservadora é lutar "passo a passo contra os pequenos distúrbios cotidianos" para reduzir as grandes "patologias criminais".

Sem comprovação empírica, essa teoria serve de álibi para conter o medo que as classes média e alta têm dos pobres nos espaços públicos (ruas, parques, estações ferroviárias, ônibus, metrô etc.). A luta que visa eliminar a criminalidade atua em três frentes: a) aumento em 10 vezes o efetivo e equipamentos das brigadas; b) restituição das obrigações operacionais aos comissários de bairro com obrigação quantitativa de resultados; c) implantação de um sistema de radar informatizado (arquivo central sinalético e cartográfico consultável em microcomputadores a bordo dos carros de patrulha). Esse conjunto de medidas possibilita uma intervenção implacável, instantânea e inflexível da lei sobre os delitos menores tais como o jogo, a mendicância, os atentados aos costumes, a simples ameaça etc.

Em termos monetários, ocorreu uma extraordinária expansão dos recursos destinados à manutenção da ordem em NY. O orçamento policial superou em quatro vezes as verbas destinadas aos hospitais públicos. Essa tendência pode ser ainda mais acentuada nos países capitalistas periféricos que entram num processo passivo de globalização decretando o fim do Estado-nação.

Em termos políticos, o rebaixamento do Legislativo em benefício do Executivo implica no enfraquecimento do contratual em favor do regulamentar. Essa inversão institucional, diz Charvet (1977), faz com que a produção da norma e sua concretização sejam subtraídas de um compromisso público em que indivíduos tenham participado.

Para os defensores do Estado policial trata-se, no entanto, do "dever de impor a obrigação" do trabalho assalariado precário. O EstadoProvidência norte-americano fracassou devido ao seu programa de ajuda à pobreza porque era permissivo e "não impunha obrigação estrita de comportamento aos seus beneficiários". O desemprego deve-se menos às opções de mercado e mais aos problemas de funcionamento pessoal 
dos desempregados. Empregos sujos e mal pagos há muitos. A situação de desemprego é, portanto, uma questão de escolha e não de escassez.

Uma questão dessa magnitude não pode ser deixada somente à boa vontade e à iniciativa dos que trabalham; por isso, devem-se adotar medidas capazes de tornar o trabalho assalariado um "dever cívico" obrigatório semelhante ao que se verifica no serviço militar. O dever da generalização do trabalho precário deve ser feito através do braço punitivo do Estado. A política social, afirma Wacquant, desistiu de cumprir a meta "de reformar a sociedade" preocupando-se em "supervisionar a vida dos pobres".

De acordo com a arquitetura da ordem criminal norte-americana, explicações estruturais da pobreza carecem de plausibilidade. Trata-se de uma questão mais relacionada ao comportamento dos pobres do que de barreiras sociais. Portanto, é o comportamento que deve mudar, mais do que a sociedade.

A existência de um Estado paternalista apenas se justifica se este vier acompanhado de uma ampla estrutura punitiva. Deve-se, por exemplo, utilizar da legislação de apoio às crianças para exigir dos pais ausentes que trabalhem para prover as necessidades de suas famílias. Políticas paternalistas de amparo à pobreza, exigindo a contrapartida do trabalho, oferecem mais esperança de melhorar a pobreza do que políticas estatais distributivas.

A proliferação das "incivilidades", dizem os defensores da nova ordem criminal, é o caminho promissor para escalada da delinquiência. As primeiras condutas "desviantes" quando não recebem punições exemplares estigmatizam um bairro e nele polarizam outros desvios como roubo, tráfico de drogas etc. As causas coletivas da ação criminal são meras desculpas porque não constituem mecanismos geradores de comportamentos delinqüentes. O crime deve ser imputado ao indivíduo e não à sociedade.

Não punir os autores das violências urbanas significa alimentar a escalada da delinqüência. Independente da fratura social é inaceitável procurar desculpas para "atos indesculpáveis". Caso contrário, todos os desempregados estariam autorizados a roubar, pilhar e depredar. A força desse discurso que prega o aumento da repressão criminal está associada ao processo mais geral de globalização em curso o qual 
impõe reformas estruturais no aparato de Estado cujo efeito tem sido o aumento da polarização econômica entre grupos e classes sociais em diversos países.

O processo de globalização econômica e financeira tem sido fértil na produção de respostas teóricas distintas no controle do crime nas sociedades contemporâneas. $\mathrm{O}$ Estado deve atuar entre os adeptos do conceito de " "normalização do crime" motivando setores da sociedade civil a oferecer respostas no campo preventivo. Nesse sentido, a gestão e o controle do crime deverão preocupar-se mais com a vitima potencial e menos com o delinquiente. Armar os alvos que propiciam inumeráveis oportunidades ao crime é o objetivo central desse modelo de política criminal.

Enquanto isso, os adeptos do chamado realismo penal sustentam que a banalização do crime na sociedade provém da complacência e do enfraquecimento da resposta da lei diante dos agentes que praticam atos criminais. No plano das políticas oficiais essa dualidade de concepções teóricas tem permeado o discurso e a ação da burocracia estatal no campo penal. Tais contradições tendem a provocar uma taxa de legitimidade social decrescente da confiança do Estado na gestão e controle do crime.

\section{Contradições da Criminologia Oficial: da Prevenção ao Aumento das Prisôes}

A criminologia oficial, informa Garland (1999), mostra-se dualista, polarizada e ambivalente. Ao lado de uma criminologia do eu que transforma o criminoso em um "consumidor racional" semelhante à vítima, opera-se ao mesmo tempo, uma criminologia do "outro", do pária, do ser ameaçador. A primeira, é invocada para banalizar e promover a ação preventiva; a segunda, para provocar o medo, as hostilidades populares e afirmar o peso punitivo do Estado(GARLAND, 1999, p.75).

No decorrer dos anos 90, verifica-se uma ambivalência do discurso oficial. Fala-se menos em "guerra contra o crime" e mais na existência de limites do poder do Estado. Documentos oficiais e manifestos políticos ressaltam que os organismos governamentais não podem combater e controlar a criminalidade isoladamente. Em razão 
disso, propõe-se "uma melhor gestão dos riscos e dos recursos, numa redução do medo, dos custos da criminalidade, da justiça criminal e maior amparo às vítimas".

Porém, nessa última década, tentativas explícitas de expressar a cólera e o ressentimento do público tornaram-se um tema recorrente da retórica que acompanha a legislação penal e a tomada de decisões. Os sentimentos da vítima, da família, de um público temeroso, ultrajado, foram constantemente invocados em apoio à criação de novas leis e políticas penais em que o "castigo" tornou-se em objeto a ser venerado.

Se, por um lado, a sociedade precisa adaptar-se ao crime concebendo-o como uma atividade profissional normal; por outro, o realismo penal sugere a divisão do crime em duas categorias: crimes violentos como terrorismo, assassinato, estupro, seqüestro, roubo, incêndio criminoso etc., exigem "uma resposta ultra repressiva" cabendo à política, responder a essa expectativa junto ao público. Já, os crimes ocasionais, como roubo de veículos, arrombamentos, vandalismo, e furtos diversos não podem esperar sucesso na ação exclusiva da polícia (GARLAND, 1999, p.64).

Esse comportamento dualista da política oficial do Estado que admite seu fracasso parcial na solução dos conflitos penais também retira das gavetas enferrujadas da história, do modelo penal clássico punitivo, antigas e falaciosas virtudes com o objetivo de administrar o crime. Nessa direção, a prisão tende a prosperar. Por quê? Porque ela funciona, afirmam seus defensores. As despesas penitenciárias são investimentos pensado e rentável para a sociedade. A triplicação da população carcerária nos Estados Unidos (1975 e 1989) teria, apenas por seu efeito neutralizante, "evitado 390.000 assassinatos, estupros, e roubos com violência".

Na falta da pena de morte, mostra Wacquant (2001), "a reclusão é de longe o meio mais eficaz de impedir os criminosos comprovados e notórios de matar, estuprar, roubar e furtar". Um sistema judiciário não tem que se preocupar com as razões que levam alguém a cometer um crime. A justiça está aí para punir os culpados, indenizar os inocentes e defender os interesses dos cidadãos que respeitam a lei. Por isso, o Estado deve punir com eficácia aqueles que insistem em transgredir a lei. 
Essa velha receita de ação repressiva estatal deve prevalecer nos EUA e em outros países ${ }^{4}$. Comportamentos criminosos ou protocriminosos como "jogar lixo na rua, insultar, pichar e cometer atos de vandalismo, devem ser reprimidos com firmeza, a fim de impedir que comportamentos criminosos mais graves se desenvolvam." Torna-se igualmente necessário restaurar o moral dos policiais que foram submetidos anos a fio ao trabalho daninho dos sociólogos e dos criminologistas, que insistem em dizer que o crime é causado pela pobreza, fora da alçada da polícia.

Mediante uma ação penal resolutamente agressiva as instituições policiais e penitenciárias na sociedade, em tempos neoliberais, pretendem reafirmar a "autoridade moral" do Estado no momento em que ele próprio é atingido pela sua impotência econômica. $\mathrm{O}$ aumento da repressão estatal, conseqüência da nova ordem criminal em vigor, vem acompanhado da privatização do sistema penitenciário. A multiplicação de prisões deve acompanhar o aumento da produção jurídica de criminosos. O mercado da punição, um negócio promissor que proporciona, aos detentores de títulos de ações das empresas de segurança, rendimentos suculentos está nascendo.

Wacquant (2001) afirma que as causas do crescimento da população carcerária norte-americana estão vinculadas aos "pequenos delinqüentes e, particularmente, dos toxicômanos". Ao contrário do discurso político e midiático dominante "as prisões estão repletas não de criminosos perigosos e violentos, mas de vulgares condenados pelo direito comum por negócios com drogas, furto, roubo ou simples atentados à ordem pública, envolvendo parcelas precarizadas das classes subalternas."

\footnotetext{
${ }^{4}$ Charvet (1977) mostra um exemplo ilustrativo dessa nova estratégica na RFA. Enquanto os cabeleireiros foram convidados a indicar as conversações suspeitas de seus clientes, coube aos bombeiros a tarefa adicional de vigiar os veículos suspeitos, reinventando, desse modo, a "delação de massa". Esse modelo de reengenharia estatal repressiva é justificado em nome da "doutrina da segurança", cujo objetivo é decretar tolerância zero aos delinqüentes. Enquanto as prisões se multiplicam, nota-se, ao mesmo tempo, uma "notável estabilidade por crimes de sangue e de costume".
} 
Em 1998, o número de condenados por contenciosos nãoviolentos reclusos "rompeu sozinha a cifra simbólica do milhão". Nas prisões, " 6 em cada 10 condenados são negros ou latinos. Menos da metade tinha emprego em tempo integral no momento de ser posta atrás das grades" (WACQUANT, 2001, p.83).

Essa mudança de objetivo e de resultado reflete "o abandono do ideal" da reabilitação, depois das críticas cruzadas da direita e da esquerda na década de 70 , e de sua substituição por uma "nova penalogia" norte-americana cujo objetivo não é mais prevenir o crime, nem tratar os delinqüentes objetivando o seu eventual retorno à sociedade. O propósito da nova ordem criminal nos EUA é isolar grupos considerados perigosos e neutralizar seus membros mais agressivos mediante uma série padronizada de comportamentos.

O reconhecimento, pelos teóricos da normalização do crime e pelos adeptos de uma política criminal ultra-repressiva, da incapacidade da burocracia estatal de gerir e controlar os litígios criminais na sociedade atual reafirma a viabilidade de fazer um questionamento teórico e político mais profundo dos paradigmas que aceitam, como um dado a priori, a existência do crime. Trata-se, portanto, de acrescentar e analisar outros movimentos políticoteóricos para uma melhor compreensão das razões da falência do modelo penal estatal existente.

\section{Globalização e Outros Fundamentos da Ação Criminal}

A justiça como aparelho de Estado acha-se em dificuldades para cumprir sua missão de regulação dos conflitos porque, comenta Charvet (1977), sua ideologia jurídica está em crise: sua legitimidade é contestada pelos dominados e sua eficiência, pelos dominantes. $\mathrm{Na}$ França, verifica-se o avanço das forças da ordem através do crescimento dos efetivos policiais, judiciários e das forças militares (guardas nas praias, rodovias e outros lugares da vida pública). Diante da crise fiscal que impede o Estado de colocar um policial atrás de cada cidadão, tende-se a criar estratégias de modo a "redescobrir e converter em um policial cada cidadão". 
A incapacidade da burocracia estatal de regular os conflitos criminais vai além do processo atual de globalização econômica e financeira. Adorno (1999) fala de um novo paradigma que aponta para algo além do crime ${ }^{5}$.

O surgimento do Estado moderno caracterizado pelo monopólio da violência e pacificação social foi acompanhado pela racionalização do direito através dos seguintes princípios: positividade, (vontade de um legislador soberano que através de meios jurídicos de organização regulamenta as atividades da vida social); legalidade (não reconhece outro ordenamento jurídico que não seja estatal e outra forma de ordenamento estatal que não seja lei); formalidade (o direito moderno define o domínio onde se pode exercer legitimamente o livre arbítrio das pessoas privadas). Esses princípios, afirma Adorno, estão sendo esfacelados.

Por volta de 1950 , ocorreu, em todos os países ocidentais, um aumento substancial dos crimes contra as pessoas e ainda mais contra o patrimônio. Um "maior número de pessoas passou a violar as leis penais" e um grande número de "comportamentos e bens protegidos pelas leis penais ficou mais vulnerável à ofensa e ao ataque".

O problema não reside nos crimes em si mas na maior ou menor disposição social em aceitá-los e conviver com eles. Ocorre que na sociedade atual essa tolerância, diz Dahrendorf apud Adorno (1999), teria chegado ao limite "haja visto (sic) as reações e a ansiedade pública diante da crescente ameaça do crime e da incapacidade da burocracia estatal em resolvê-lo".

A erosão da lei e da ordem está vinculada à maior probabilidade de um criminoso se manter oculto, hoje, comparativamente ao passado. Uma taxa desprezível dos crimes cometidos é resolvida em razão do descaso da política pelos delinqüentes conhecidos, desistência deliberada e afrouxamento das punições ou incapacidade de se lidar com as infrações. A impunidade aumenta e põe em questão a eficácia das normas. Isso provoca a sensação de "inexistência das leis ou,

${ }^{5}$ O novo paradigma, afirma Adorno (1999, p.77), diz "respeito à mudança de hábitos, à exacerbação de novos conflitos sociais, à adoção de soluções que desafiam tradições democráticas, à demarcação de novas fronteiras sociais [...] ao sentimento de desordem e caos que se espelha na ausência de justiça social". 
quando invocadas, resultam sem efeito". As sociedades contemporâneas convivem com o "declínio das sanções". A impunidade torna-se cotidiana diante da decretada incapacidade da burocracia estatal de cuidar da segurança dos cidadãos, de proteger seus bens materiais e simbólicos.

Os mecanismos de pressão social (que atuam sobre o comportamento dos sujeitos) que operam, sobretudo, na esfera da moralidade pública e privada não parecem suscitar nem o sentimento de medo, nem sequer o de angústia diante das possibilidades, sempre abertas, de violação das normas sociais. As sociedades urbanas complexas, comenta Adorno (1999), liberaram o homem do controle social. Diante de tantas incertezas cresce, por parte da sociedade, uma obsessão punitiva reivindicando mais "ordem social".

Isso não impede o surgimento do modelo de funcionamento da sociedade de risco que põe em movimento uma superestrutura de prevenção e de segurança por meio da proliferação das sociedades de seguro e de mecanismos de vigilância privada com o objetivo de enfrentar o medo, os perigos e ameaças que tornam a vida humana incerta (ADORNO, 1999, p.101-102).

Um política de responsabilização individual através de medidas repressivas voltadas para os jovens delinqüentes, como a redução da idade para efeitos de responsabilidade penal e instauração da responsabilidade dos pais em matéria civil e penal, tem sido discutida pelos parlamentares europeus. Enveredando-se pelo caminho de mais Estado econômico e menos Estado social, cria-se e justifica-se o mito da inevitabilidade da escalada do crime para disseminar a estratégia da responsabilização como forma de mostrar que a prevenção e o controle do crime não pode, de modo exclusivo, recair mais sobre o Estado.

De agora em diante, varejistas, industriais, autoridades escolares, empresas de transporte, pais, trabalhadores e desempregados terão de dividir essa responsabilidade. Na década de 1990 a política criminal da responsabilização teve por efeito reduzir a dependência para com o Estado e aumentar a dependência para com o mercado. Investimentos na criminalidade como "dispositivos de segurança", são cada vez mais impostos pelas forças econômicas em detrimento da "política pública".

Nas sociedades onde ocorrem divisões sociais e raciais 
profundas, em que as taxas de criminalidade e os níveis de insegurança são elevados, onde soluções sociais foram politicamente desacreditas, além de haver um ceticismo crescente quanto à perspectiva de reintegração dos antigos delinqüentes, um setor comercial em expansão favorece o aumento da população carcerária pondo em marcha uma cultura do encarceramento em massa nos países democráticos.

A responsabilização de organismos não estatais no combate à criminalidade provoca enormes disparidades no financiamento social e na rede de segurança. Esta, deixa de ser garantida para todos por meio de um Estado soberano para converte-se num produto cuja distribuição está subordinada às forças de mercado. As classes subalternas, que mais sofrem a criminalidade, estão incapacitadas de comprar segurança, de adaptar suas vidas cotidianas e de se organizar de forma eficaz contra o crime.

Políticas sociais de prevenção da criminalidade foram seriamente atacadas em razão das transformações políticas sociais e econômicas das últimas décadas. Tentativas de prevenção e de responsabilização são solapadas por uma economia de livre mercado que exclui as massas do trabalho remunerado e que nutre ativamente o crime, engendrando expectativas de consumidor insaciável gerando, ao mesmo tempo, novos níveis de pobreza da criança, da disfunção da família e de desigualdade social (GARLAND, 1999, p.77).

A emergência de novos problemas sociais que desafiam os princípios legitimadores do Estado moderno tende a acelerar; porém, em si, não justifica o fracasso da burocracia oficial na resolução dos atos infracionais na sociedade contemporânea. Os sintomas aparentes de desordem, de caos, de aumento da impunidade etc., que reinam na sociedade vão muito além de uma política criminal deliberada de afrouxamento do poder estatal como estratégia de administrar os conflitos criminais.

A crise de legitimidade estatal na gestão do crime reforça a necessidade de pôr em questão a definição de crime como verdade ontológica. O propósito do próximo capítulo é avaliar e discutir se os eventos sociais considerados problemáticos e penalmente definidos como crimes na sociedade, são, por esta, reconhecidos e aceitos como tais na realidade. 


\section{Da Descriminalização à Abolição da Pena}

A crise profunda da justiça penal, avalia Cervini (1995), está associada "ao fracasso da ideologia do tratamento" que pretende em seus diversos níveis resolver os custos individuais e sociais do delito, a defasagem das leis com certas culturas, a existência da cifra negra ${ }^{6}$, além das contradições dogmáticas.

No momento histórico atual, diz Cervine, dois fatores favorecem a tendência de descriminalização do direito penal: um individual, outro social. No primeiro caso, a pena privativa de liberdade que diminui a possibilidade de adaptabilidade; no segundo caso, os efeitos sociais estigmatizadores depois de sua aplicação. Em termos sociais, não há uma solução eficiente em reparar o custo do crime nem de supressão do estigma de ex-presidiário.

As soluções que o sistema penal tem adotado para gerir o problema da criminalidade encontram um potente antídoto quando se avalia a existência da chamada cifra negra. Essa, afirma Cervine, indica claramente que os fatos aos quais a lei denomina de delitos não são considerados "como fatos à parte" separados de outros acontecimentos. Uma soma relevante de "acontecimentos formalmente considerados delitos e teoricamente merecedores de aplicação penal" não é considerada, nem valorizada como tal pelas vítimas ou pelos agentes do sistema, pessoalmente interpelados mediante delações concretas (CERVINI, 1995, p.173).

Tais considerações colidem com as premissas utópicas da sociedade de controle que busca incansavelmente definir e administrar o crime através da diversificação das penas, de ajustes da reclusão prisional, de reforma eletrônica das prisões, mais investimentos e maior eficiência na burocrática criminal. A sociedade de controle, diz Passetti (1999), não atenta para o fato da existência de uma sociedade sem penas, seja em

\footnotetext{
${ }^{6}$ Cervini (1995, p.162) comenta que a cifra negra é produto da diferença existente entre a criminalidade real, quantidade de delitos cometidos num tempo e lugar determinados, e a criminalidade aparente, conhecida pelos órgãos de controle. $\mathrm{Ou}$ seja, um percentual substancial de delitos está estruturalmente fora do alcance e do controle do direito penal, colocando em xeque a credibilidade de todo o sistema.
} 
razão da cifra negra (diferença entre infrações denunciadas na polícia e aquelas efetivamente julgadas) seja porque parte considerável das infrações é resolvida sem a necessidade da formalidade jurídica do justo 7 .

A maioria dos conflitos cotidianos dentro das famílias, das empresas, dos estabelecimentos de ensino, das organizações profissionais, dos sindicatos, clubes ou associações privadas são, segundo Hulsman e Celis (1993), resolvidos sem ter de entrar no sistema penal. O grande número de encarcerados é insignificante diante da quantidade real de fatos puníveis que ocorrem a todo instante, raramente detectados pelo sistema penal. O sistema penal é confrontado com uma espantosa soma de casos semelhantes, porém, apenas alguns deles e, de forma injusta, são tratados pelo sistema cuja prisão se nutre diariamente de vítimas preferencias.

Fora os delitos que não pertencem ao chamado "núcleo duro da delinquiência' como o terrorismo e a criminalidade organizada, o sistema penal, afirma Hulsman, cria mais problemas do que contribuições para resolver.

Diante disso, o autor propõe uma outra lógica. Diz que um comportamento pode deixar de ser crime sem afetar os laços de sociabilidade. $\mathrm{O}$ homossexualismo, cantado em prosa e verso por Platão, foi penalmente condenado pelo Estado moderno durante muito tempo. A prostituição convive com a proibição sob ameaça penal até a liberdade total, ou passando por toda sorte de controle administrativo. A embriaguez em si não interessa à lei ocidental mas só indiretamente (dirigir embriagado). O mesmo tratamento diferencial ocorre em relação ao uso e ao tráfico de drogas. Alguns países condenam penalmente o uso e o tráfico excluindo o consumo pessoal. Outros só colocam no campo penal as drogas ditas pesadas excluindo as chamadas drogas leves ${ }^{8}$

\footnotetext{
${ }^{7} \mathrm{Na}$ opinião de Passetti (1999, p.63), o que esta utopia não admite mas permitia é que no lugar da ressocialização e da futura reintegração prevaleça o depósito de corpos para os quais os únicos investimentos são a diminuição, a zero, da possibilidade de fuga e a rigorosa vigilância após o sentenciamento.

* Na avaliação de Hulsman e Celis (1993, p.101), não existem nem crimes nem delitos mas apenas "situações problemáticas". Sem a presença e participação das pessoas envolvidas nestas situações, não há como resolvê-las de forma humana. Classificar um fato de crime significa excluir a priori outras saídas possíveis, limitando-se ao estilo estatal punitivo, dominado pelo pensamento jurídico distante da realidade.
} 
O processo de globalização econômica e financeira apenas indiretamente contribui para aprofundar a crise do sistema de justiça penal nos países capitalistas centrais e periféricos. As razões da falência do modelo de política criminal estão associadas ao processo de reforma penal dos séculos XVIII e XIX, período em que a sociedade burguesa adotou o principio da punição generalizada por meio da teoria da humanização da pena. A reforma do código penal burguês, diz Foucault (1987), converteu inúmeros problemas sociais em conflitos criminais, estabeleceu uma classificação metódica dos delitos em termos de gravidade e hierarquia e, como complemento, modificou e converteu as prisões em locais privilegiados com o propósito de recuperar os delinqüentes infratores através do tratamento ressocializador.

Desde então, todas as propostas adotadas visando a reforma do sistema penal não tocaram e não discutiram seriamente o significado do crime, sua classificação, tampouco sua instituição correlata, a prisão. As teorias criminais da normalização e da defesa da lei e da ordem (tolerância zero) são ilustrativas a esse respeito.

A primeira, vê no crime uma ação racional oportunista. Parte do pressuposto de que a sociedade atual é uma sociedade de risco em que o fenômeno criminal não pode ser tratado como algo patológico, mas uma questão de oportunidade. Propõe desativar a burocracia estatal repressiva por ter falhado na tentativa de desarmar e de punir o autor do delito e transferir a responsabilidade do controle do crime aos setores da sociedade civil. Grupos privados deveriam armar os alvos vulneráveis, criar obstáculos, defender suas casas, carros, cheques, cartões de crédito etc. Tais mudanças tornariam as coisas mais difíceis evitando que pessoas pertencentes aos diversos grupos sociais se convertessem em presas fáceis de ações criminais.

A segunda (movimento da lei e da ordem) associa a banalização do crime à fraqueza das respostas das leis penais vigentes. Por isso advoga a necessidade de uma perseguição implacável de pequenos atos como jogar lixo no chão e furtos ocasionais, propondo o aumento da pena para os delinqüentes ocasionais e a prisão perpétua para os delinqüentes mais perigosos. $\mathrm{O}$ que diferencia as teorias criminais em foco é mais uma questão de estratégia e não de princípios. Ambas trabalham com a noção de crime como uma verdade social e jurídica. 
A negação do conceito de crime como um fato social normal constitui objeto de reflexão das teorias da descriminalização e abolicionistas, para as quais as definições abstratas de crime e de pena vigentes no código penal não correspondem às definições que delas fazem as pessoas reais. A desqualificação do discurso jurídico penal não resulta, portando, das dificuldades da aplicação da lei, da ineficiência dos órgãos de controle criados para administrá-la, ou, ainda, de seu reduzido alcance quando se compara a totalidade de crimes formalmente descritos e os que realmente são solucionados.

Uma solução política socialmente legítima na solução dos problemas sociais, hoje definidos e classificados como problemas criminais, não pode limitar-se ao entendimento e à aceitação do braço punitivo estatal e de sua burocracia centralizadora como o melhor remédio para gerir os conflitos penais existentes. Portanto, torna-se urgente questionar seriamente se os eventos sociais formalmente criminalizáveis são concebidos e aceitos como tais pelos agentes sociais direta e potencialmente envolvidos em tais conflitos.

Isso implica admitir a possibilidade da sociedade resolver inúmeros problemas, atualmente circunscritos no campo do direito penal, fora do campo estatal punitivo. Nesse sentido, a responsabilidade pela solução dos conflitos, sob a tutela do direito penal, seria transferida aos agentes direta e potencialmente envolvidos em situações problemáticas (acusado, vítima, familiares, Estado e demais interessados).

A atuação da burocracia de justiça (polícia e judiciário) se limitaria a mediar e não intervir diretamente visando impor a melhor solução para o conflito. Para isso, outras instâncias jurídicas (campo civil e administrativo) poderiam ser acionadas em detrimento do pesado, seletivo e ineficiente sistema de justiça penal estatal vigente que por meio de seus órgãos policiais, judiciários e administrativos, procura sem nunca poder encontrar a melhor solução para o acusado, seus familiares, à vitima e a sociedade.

Dois adolescentes (Japonês e Lázaro) praticaram mais um delito contra o patrimônio. E daí? Prendê-los, ressocializá-los, responsabilizar seus familiares? Armar melhor determinados alvos sociais vulneráveis que facilitam o roubo, o furto? 
Como ressocializar alguém que, por razões conjunturais como o desemprego e a crise econômica, pratica um delito contra a propriedade, se tais razões continuam a persistir? Como responsabilizar seus familiares ${ }^{9}$, se a concepção nuclear de família burguesa mudou?

Para os defensores do movimento da lei e da ordem o Estado deve responder punindo de modo exemplar. Entre os adeptos da normalização do crime, o Estado deve preocupar-se em punir menos e criar uma nova estratégia com o propósito de armar mais as vítimas que os infratores.

Tais movimentos não tocam numa questão central como o fazem os adeptos da descriminalização e da abolição da pena, para os quais, a realidade atual propicia duas alternativas: procurar outras repostas para os velhos e novos problemas questionando, reduzindo e abolindo o crime e a prisão, ou restaurá-la sob a condição de "aparelho de terror repressivo".

${ }^{9}$ Passetti (1995, p.23) afirma que a situação social dessas crianças e adolescentes violentados permite desmistificar duas falácias: famílias desestruturadas; e o suposto acesso democrático à escola. O modelo de família vigente nas metrópoles, não corresponde mais às características da família modelar burguesa do capitalismo livre-concorrência e não pode mais ser restaurada como pretende o conservadorismo. 


\section{Referências}

ADORNO, S. Violência e civilização. In: CONGRESSO BRASILEIRO DE SOCIOLOGIA, 9., 1999, Pelotas. Anais... Pelotas: Sociedade Brasileira de Sociologia, 1999. p.77-106.

BARATTA, Alessandro. Escola positiva e explicação patológica da criminalidade. In: - Criminologia crítica e crítica do direito penal: introdução à sociologia do direito penal. 3.ed. Rio de Janeiro: Revan, 2002.

CERVINI, Raúl. Os processos de descriminalização. 2.ed. São Paulo: Revista dos Tribunais, 1995

CHARVET, D. Crise da Justiça, da lei, crise do Estado. In: POULANTZAS, N. (Org.). O Estado em crise. Rio de Janeiro: Graal, 1977.

CHESNAIS, François. Mundialização: o capital financeiro no comando. Outubro: Revista do Instituto de Estudos Socialistas, São Paulo, n.5, p.7-42, 2001.

DOWBOR, Ladislau; IANNI, Octavio; RESENDE, Paulo Edgar (orgs.). Desafios da Globalização. Petrópolis: Vozes, 1998.

FOUCAULT, Michel. Vigiar e punir: história da violência nas prisões. 23.ed. Petrópolis: Vozes, 1987.

GARLAND, David. As contradições da sociedade punitiva: o caso britânico. Revista de Sociologia e Política, Curitiba, n.13, p.59-80, nov. 1999.

HULSMAN, Louk; CELIS, Jacqueline Bernat de. Penas perdidas: o sistema penal em questão. Rio de Janeiro: Luam, 1993.

OHMAE, Kenichi. O fim do Estado Nação: a ascensão das economias regionais. 3.ed. São Paulo: Campus, 1999.

PASSETTI, Edson (Org.). Violentados: crianças, adolescentes e justiça. São Paulo: Imaginário, 1995.

PASSETTI, Edson. Sociedade de controle e abolição da punição. Violência e Mal-Estar na Sociedade. São Paulo em Perspectiva, São Paulo, v.13, n.3, jul/ set/1999.

SANTOS, Boaventura Sousa. A crítica da razão indolente: contra o desperdício da experiência. São Paulo: Cortez, 2000. v.1.

WACQUANT, Loïc. As prisões da miséria. Rio de Janeiro: Zahar, 2001. 


\section{Abstract}

The current process of economic and financial globalization has elicited contradictory answers in the formulation of criminal policies by State bureaucracy. On the one hand, under strong influence of neoclassical economic thought, there appears in the United Kingdom the theory of crime normalization, qualifying the criminal act as a rational choice option, a matter of opportunity, according to which delinquents rationally calculate their actions. Such theory proposes to replace the classical model of criminal policy, which relates the penal practice to the figure of the "other", the "abnormal"., by a new model of 'risk society', which sees a professional career in criminal acts. On the other hand, there appears in the United States the movement in defense of law and order, which proposes no tolerance to crime by the amplification of penal right and the recrudescence of the State criminal answer. For the defenders of decriminalization and penal abolitionism the utopia of control society which favors the increase of punishment and target changes to administer crime ignores the existence of a society with no penalties which is manifested through the dark cipher, the difference between reported infractions to the police and those really judged.

Key words: globalization; state; crime; punishment; decriminalization; penalty abolishment 